\title{
Fatty-acid binding protein 4 gene variants and childhood obesity: potential implications for insulin sensitivity and CRP levels
}

\author{
Abdelnaby Khalyfa', Bharat Bhushan', Mohamed Hegazi ', Jinkwan Kim', Leila Kheirandish-Gozal',
} Rakesh Bhattacharjee ${ }^{2}$, Oscar Sans Capdevila ${ }^{3}$, David Gozal ${ }^{1 *}$

\begin{abstract}
Introduction: Obesity increases the risk for insulin resistance and metabolic syndrome in both adults and children. FABP4 is a member of the intracellular lipid-binding protein family that is predominantly expressed in adipose tissue, and plays an important role in maintaining glucose and lipid homeostasis. The purpose of this study was to measure FABP4 plasma levels, assess FABP4 allelic variants, and explore potential associations with fasting glucose and insulin levels in young school-age children with and without obesity.
\end{abstract}

Methods: A total of 309 consecutive children ages 5-7 years were recruited. Children were divided based on BMl z score into Obese (OB; BMl z score >1.65) and non-obese (NOB). Fasting plasma glucose, lipids, insulin, hsCRP, and FABP4 levels were measured. HOMA was used as correlate of insulin sensitivity. Four SNPs of the human FABP4 gene (rs1051231, rs2303519, rs16909233 and rs1054135), corresponding to several critical regions of the encoding FABP4 gene sequence were genotyped.

Results: Compared to NOB, circulating FABP4 levels were increased in $\mathrm{OB}$, as were LDL, hsCRP and HOMA. FABP4 levels correlated with BMl, and also contributed to the variance of HOMA and hsCRP, but not serum lipids. The frequency of rs 1054135 allelic variant was increased in $\mathrm{OB}$, and was associated with increased FABP4 levels, while the presence of rs16909233 variant allele, although similar in OB and NOB, was associated with increased HOMA values.

Conclusions: Childhood obesity is associated with higher FABP4 levels that may promote cardiometabolic risk. The presence of selective SNPs in the FABP4 gene may account for increased risk for insulin resistance or systemic inflammation in the context of obesity.

\section{Introduction}

Childhood obesity is a serious public health problem that has reached epidemic proportions all over the world [1-3]. Metabolic and cardiovascular complications of obesity in childhood, while less common than in adulthood, may nevertheless include hyperlipidemia, insulin resistance and type 2 diabetes, and systemic low grade inflammation.

In children, the presence of obesity has been associated with increased levels of high sensitivity CRP (hsCRP) [4], as well as other inflammatory mediators

\footnotetext{
* Correspondence: dgozal@peds.bsd.uchicago.edu
'Department of Pediatrics, Comer Children's Hospital, The University of

* Correspondence: dgozal@peds.bsd.uchicago.edu
'Department of Pediatrics, Comer Children's Hospital, The University of Chicago, Chicago, IL, USA
}

(c) 2010 Khalyfa et al; licensee BioMed Central Ltd. This is an Open Access article distributed under the terms of the Creative Commons Attribution License (http://creativecommons.org/licenses/by/2.0), which permits unrestricted use, distribution, and reproduction in any medium, provided the original work is properly cited.

[5-9], all of which promote the development of endothelial and metabolic dysfunction [10-14]. However, substantial variability is found among obese children as to the presence of metabolic dysfunction or increased inflammatory markers, suggesting that individual genomic variance may account for such discrepancies.

Fatty acid binding proteins (FABP) are a group of related molecules that serve as intracellular chaperones for lipid moieties, coordinate cellular lipid responses, and thereby play a critical role in metabolic and inflammatory pathways $[15,16]$. Adipocyte FABP, also known as FABP4, A-FABP, or aP2, was initially detected in mature adipocytes, and plays critical roles in hyperlipidemia, atherogenesis and type 2 diabetes, particularly 
when obesity is concurrently present $[17,18])$. FABP4 is produced and released to the circulation, and FABP4 levels appear to correlate with the degree of metabolic dysfunction $[19,20]$. Similar to adults, children who are obese are more likely to display elevations in FABP4 plasma levels, which will be reduced by interventions leading to weight loss [21,22].

We hypothesized that the presence of obesity in community based children will be associated with increased FABP4 levels which may account for individual discrepancies in the presence or absence of insulin resistance or high sensitivity C-reactive protein (hsCRP) plasma levels, and that single nucleotide polymorphisms in the FABP4 gene may underlie the variance in such relationships.

\section{Subjects and Methods Subjects}

The study was approved by the University of Louisville Human Research Committee, and informed consent was obtained from the legal caregiver of each participant. Consecutive children between the ages of 5 to 7 years attending public schools in Jefferson County were invited to participate in the study, after they underwent a schoolbased health screening, which included height and weight measurements. Based on such screening, children were identified when their BMI z score was $\geq 1.65(\mathrm{OB})$ and age-, gender-, ethnicity-, and area-of residence-matched children with BMI z scores $<1.65$ (NOB) were then identified and recruited to serve as controls. Of note, all children were otherwise healthy, and were representative of the demographic characteristics of the general population of the city of Louisville http://ksdc.louisville.edu/sdc/census2000/cityprofiles/LouisvilleDP.pdf. Children were excluded if they had known diabetes or pre-diabetes http://www.diabetes.org/pre-diabetes/pre-diabetes-symptoms.jsp, any defined genetic abnormality or underlying systemic disease including hypertension, or if they were within a month from any acute infectious process.

\section{Anthropometry}

To verify the school-health screening initial reports, children were weighed in a calibrated scale to the nearest $0.1 \mathrm{~kg}$ and height (to $0.1 \mathrm{~cm}$ ) was measured with a stadiometer (Holtain, Crymych, UK). Body mass index (BMI) was calculated and BMI z-score was computed using CDC 2000 growth standards http://www.cdc.gov/ growthcharts and online software http://www.cdc.gov/ epiinfo. A BMI z score $\geq 1.65$ was considered as fulfilling the criteria for obesity.

\section{Blood Based Assays}

Blood samples were drawn by venipuncture in the morning after an overnight fast. Blood samples were immediately centrifuged and plasma was frozen at $-80^{\circ} \mathrm{C}$ until assay. Plasma insulin levels were measured using a commercially available radioimmunoassay kit (Coat-ACount Insulin; Diagnostic Products Inc). This method has a detection level of $1.2 \mu \mathrm{IU} / \mathrm{mL}$ and exhibits linear behavior up to $350 \mu \mathrm{IU} / \mathrm{mL}$, with intra-assay and interassay coefficients of variability of $3.1 \%$ and $4.9 \%$, respectively. Plasma glucose level was measured using a commercial kit based on the hexokinase-glucose-6-phosphate dehydrogenase method (Flex Reagent Cartridges; Dade Behring, Newark, DE). Insulin resistance was assessed using the homeostasis model assessment (HOMA) equation (fasting insulin $\times$ fasting glucose/ 22.5) [23].

Plasma hsCRP levels were measured within 2-3 hours after collection using the Flex reagent Cartridge (Date Behring, Newark, DE). This method has a detection level of $0.05 \mathrm{mg} / \mathrm{dl}$, and exhibits linear behavior up to $255 \mathrm{mg} / \mathrm{dl}$, with intra-assay and inter-assay coefficients of variability of $9 \%$ and $18 \%$ respectively for hsCRP. Serum lipids including total cholesterol, high-density lipoprotein (HDL) cholesterol, calculated low-density lipoprotein cholesterol (LDL), and triglycerides (TG) were also assessed using Flex Reagent Cartridges (Dade Behring).

Plasma FABP4 levels were also measured using commercial ELISA kits (ALPCO Diagnostics, Salem, NH) following the manufacturer's instructions. All assays were performed in duplicate and a calibration curve was included in each assay.

\section{DNA Extraction}

Peripheral blood samples were collected in vacutainer tubes containing EDTA (Becton Dickinson, Franklin Lakes, NJ, USA). All DNA samples were extracted using QIAmp DNA blood kit (Qiagen, Valencia, CA) according the manufacturer's protocol. The concentration and quality of the DNA were determined using a ND-1000 Spectrophotometer (Nanodrop Technologies, Wilmington, DE, USA). The purity of the DNA were determined by calculating the ratio of absorbance at $260 / 280 \mathrm{~nm}$, and all DNA samples had a ratio of 1.8-1.9. The precise length of genomic DNA was determined by gel electrophoresis using $1 \%$ agarose gel. All the purified samples were stored at $-80^{\circ} \mathrm{C}$ until further analyses.

\section{Genotyping using Real-Time PCR}

Genotyping was performed using the ABI PRISM 7500 Sequence Detection System for allelic discrimination following the manufacturer's instructions (Applied Biosystems). Four FABP4 single nucleotide polymorphisms, namely rs1051231, rs2303519, rs16909233 and rs1054135 were examined in this study (Applied Biosystems). All polymorphisms were genotyped using 
TaqMan technology (Applied Biosystems, Inc.). Two fluorogenic minor groove binder probes were used for each locus using the dyes 6-carboxyfluorescein (FAM; excitation, $494 \mathrm{~nm}$ ) and VIC (excitation, $538 \mathrm{~nm}$ ) which are easily differentiated in PCR system. Real-time PCR reaction was performed using $12.5 \mu \mathrm{l}$ of TaqMan $2 \times$ universal master mix (Applied Biosystems, CA), $1.25 \mu \mathrm{l}$ of SNP, $10.25 \mu \mathrm{l}$ of RNase- and DNase-free water (Ambion, Austin, TX), and $1 \mu$ l of sample DNA, in a total volume of $25 \mu$ per single well reaction. Two wells of a 96 well-plate (Applied Biosystems, CA) were used for each sample for each of the 4 single nucleotide polymorphisms. DNase-free water used as non-template control was included in each assay run. Assay conditions were $2 \mathrm{~min}$ at $50^{\circ} \mathrm{C}, 10 \mathrm{~min}$ at $95^{\circ} \mathrm{C}$, and 40 cycles of $95^{\circ}$ $\mathrm{C}$ for $15 \mathrm{~s}$ and $60^{\circ} \mathrm{C}$ for $1 \mathrm{~min}$. Initially, the SNP assay was set up using SDS, version 2.1, software (Applied Biosystems, CA) as an absolute quantification assay, but after assay completion the plate was read using the allelic discrimination settings. Post-assay analysis was performed using the SDS software.

\section{Statistical Analysis}

Data were expressed as mean \pm SD. Significant differences within groups were analyzed using ANOVA for continuous variables and chi-square tests for categorical variables. Spearman's correlation analyses were conducted to examine potential associations between BMI and plasma concentrations of the various inflammatory mediators. Statistical analyses were performed using SPSS software (version 16.0; SPPS Inc., Chicago, Ill.). All p-values reported are 2-tailed with statistical significance set at $<0.05$.

\section{Results}

A total of $182 \mathrm{OB}$ children and 127 age-, gender- and ethnicity-matched NOB children were recruited during January to May 2008. The demographic characteristics of this cohort are shown in Table 1, and are virtually identical to the published demographics of the city of Louisville, Kentucky.

As anticipated, OB children had higher HOMA values, indicative of insulin resistance, and also exhibited higher LDL, VLDL, and TG levels and lower HDL concentrations compared to NOB children (Table 1). OB children also had significantly higher levels of hsCRP and FABP4 than NOB (Table 1).

FABP4 levels were positively correlated with BMI z score ( $\mathrm{r}: 0.57 ; \mathrm{p}<0.0001)$. hsCRP and HOMA were also significantly associated with FABP4 $(\mathrm{r}=0.29$; $\mathrm{p}<0.001$ and $\mathrm{r}=0.18 ; \mathrm{p}<0.01$, respectively). However, FABP4 levels did not exhibit any linear correlation with lipid levels. Multivariate analyses of variance revealed that after adjusting for BMI $\mathrm{z}$ score, FABP4 contributed to
Table 1 Demographic characteristics and fasting morning plasma concentrations of lipids, glucose, insulin, hsCRP, and FABP4 in obese and matched non-obese children

\begin{tabular}{lccc}
\hline & $\begin{array}{c}\text { OB } \\
(\mathbf{n}=\mathbf{1 8 2})\end{array}$ & $\begin{array}{c}\text { NOB } \\
(\mathbf{n}=\mathbf{1 2 7})\end{array}$ & P-value \\
\hline Age (years) & $6.7 \pm 0.4$ & $6.7 \pm 0.4$ & \\
Gender (\% male) & 51.4 & 51.9 & \\
Ethnicity & & & \\
White Caucasian \% & 75.7 & 76.6 & \\
African American \% & 18.9 & 18.2 & \\
BMI z score & $2.04 \pm 0.23$ & $0.91 \pm 0.12$ & $<0.00001$ \\
Cholesterol & $176.5 \pm 3.1$ & $164.4 \pm 2.5$ & $\mathrm{NS}$ \\
Triglycerides & $85.1 \pm 4.1$ & $70.4 \pm 2.9$ & $<0.01$ \\
HDL & $49.6 \pm 1.5$ & $58.7 \pm 1.0$ & $<0.01$ \\
VLDL & $18.9 \pm 1.4$ & $15.7 \pm 0.9$ & $<0.02$ \\
LDL & $98.4 \pm 2.4$ & $87.4 \pm 2.1$ & $<0.002$ \\
Glucose & $81.3 \pm 1.3$ & $78.2 \pm 1.7$ & $\mathrm{NS}$ \\
Insulin & $12.9 \pm 1.3$ & $6.5 \pm 1.0$ & $<0.001$ \\
HOMA & $2.6 \pm 0.3$ & $1.4 \pm 0.3$ & $<0.001$ \\
hsCRP ((mg/dl)) & $2.67 \pm 0.48$ & $1.04 \pm 0.13$ & $<0.001$ \\
FABP4 (ng/mL) & $21.4 \pm 1.2$ & $12.1 \pm 1.0$ & $<0.0001$ \\
\hline
\end{tabular}

$9 \%$ of the variance in hsCRP $(\mathrm{p}<0.003)$ and $3 \%$ of the variance in HOMA $(\mathrm{p}<0.05)$.

The frequency of each of the FABP4 polymorphisms is shown in Table 2 for $\mathrm{OB}$ and NOB children. Obese children showed increased frequency of rs1054135 polymorphism compared to control children. There were no differences between $\mathrm{OB}$ and $\mathrm{NOB}$ for the other 3 polymorphisms.

Only the rs1054135 polymorphism showed significant contributions to higher FABP4 plasma levels (Table 3). In contrast, obesity interacted with rs16909233 allelic variance, such that the presence of this single nucleotide polymorphism in the context of obesity was associated with higher HOMA values, indicative of insulin resistance $(\mathrm{p}<0.001)$.

Table 2 Allelic distribution of FABP4 SNPs in obese and non-obese children.

\begin{tabular}{ccccc}
\hline SNP & Allele & OB $(\mathbf{n}=\mathbf{1 8 2})$ & NOB $(\mathbf{n}=\mathbf{1 2 7})$ & $\boldsymbol{p}$ value \\
\hline rs1054135 & GG & $61(33.5)$ & $135(74.2)$ & $<0.001$ \\
& GA & $73(40.1)$ & $26(14.3)$ & \\
rs1051231 & AA & $48(26.4)$ & $19(10.4)$ & \\
& AA & $182(100)$ & $127(100)$ & N/A \\
& AC & 0 & 0 & \\
rs2303519 & CC & 0 & 0 & \\
& CC & $116(63.7)$ & $100(78.7)$ & 0.13 \\
& CT & $65(36.25)$ & $26(20.4)$ & \\
rs16909233 & GT & $1(0.05)$ & $1(0.9)$ & \\
& GG & $129(70.8)$ & $99(77.9)$ & 0.26 \\
& AG & $52(28.6)$ & $26(20.5)$ & \\
& AA & $1(0.6)$ & $2(1.6)$ & \\
\hline
\end{tabular}


Table 3 HOMA and FABP4 plasma levels in variant and wild allele of SNPs in obese and non-obese children.

\begin{tabular}{|c|c|c|c|c|c|c|}
\hline \multirow{2}{*}{$\begin{array}{c}\text { SNPs } \\
\text { rs1054135 G/A }\end{array}$} & \multicolumn{2}{|c|}{ OB $(n=182)$} & \multirow[t]{2}{*}{$p$ value } & \multicolumn{2}{|c|}{ NOB $(n=127)$} & \multirow[t]{2}{*}{$p$ valu } \\
\hline & $A+(n=121)$ & A- $(n=61)$ & & $A+(n=35)$ & A- $(n=92)$ & \\
\hline FABP4 levels & $22.5 \pm 5.5$ & $16.1 \pm 2.4$ & $<0.001$ & $12.5 \pm 3.5$ & $7.7 \pm 2.3$ & $<0.001$ \\
\hline HOMA & $2.5 \pm 0.7$ & $2.6 \pm 0.5$ & $>0.05$ & $1.5 \pm 0.4$ & $1.3 \pm 0.4$ & $>0.05$ \\
\hline $\mathrm{rs} 1051231 \mathrm{~A} / \mathrm{C}$ & $C+(n=0)$ & $C-(n=186)$ & & $C+(n=0)$ & $C-(n=123)$ & \\
\hline FABP4 levels & N/A & $19.2 \pm 4.3$ & $N / A$ & N/A & $9.1 \pm 3.4$ & $N / A$ \\
\hline $\mathrm{rs} 2303519 \mathrm{C} / \mathrm{T}$ & $T+(n=66)$ & $T-(n=116)$ & & $T+(n=27)$ & $T-(n=100)$ & \\
\hline FABP4 levels & $19.7 \pm 5.4$ & $19.7 \pm 5.3$ & $>0.05$ & $11.3 \pm 3.2$ & $10.2 \pm 3.1$ & $>0.05$ \\
\hline HOMA & $2.5 \pm 1.0$ & $2.6 \pm 0.5$ & $>0.05$ & $1.4 \pm 0.4$ & $1.4 \pm 0.4$ & $>0.05$ \\
\hline rs16909233 G/A & $A+(n=53)$ & A- $(n=129)$ & & $A+(n=28)$ & A- $(n=99)$ & \\
\hline FABP4 levels & $19.2 \pm 5.6$ & $19.2 \pm 5.2$ & $>0.05$ & $11.0 \pm 2.7$ & $10.8 \pm 3.3$ & $>0.05$ \\
\hline HOMA & $3.1 \pm 1.1$ & $2.2 \pm 0.9$ & $<0.001$ & $1.5 \pm 0.4$ & $1.4 \pm 0.4$ & $>0.05$ \\
\hline
\end{tabular}

\section{Discussion}

In this study, we show that FABP4 plasma levels are significantly higher in obese children and correlate with measures of insulin resistance and systemic inflammation, such as HOMA and hsCRP, respectively. Furthermore, the frequency of the rs1054135 single nucleotide polymorphism in the FABP4 gene was higher in $\mathrm{OB}$ compared to NOB, and seemingly contributes to higher FABP4 levels, while the presence of rs16909233 is associated with insulin resistance in the context of obesity.

Before we discuss the potential implications of these findings, some methodological issues deserve comment. This was a community study that was designed such as to be as representative as possible of the ethnic distribution of the population of Louisville, and a priori excluded any child with known diabetes, hypertension or another chronic disease condition associated with obesity. Such methodological approach may have artificially reduced the impact of obesity on FABP4 levels as well as the magnitude of the association of any given FABP4 allelic variant with the degree of metabolic dysfunction or FABP4 plasma levels. Therefore, it will be important to explore such possibilities in a clinical referral obese pediatric population. Secondly, we restricted the age range of our cohort to a narrow time window that is associated with the initial 3 years of attendance within the public school system, a period that coincides with significant changes in food consumption patterns $[24,25]$. Such decision aimed to reduce as much as possible the presence of confounders across a wide age spectrum. Finally, we identified and recruited closely matching control children in the same school for each obese child that was recruited, such as to nullify as best as possible some of the known potential confounders that could be introduced in the process of cohort selection.

FABP4 has been proposed as a bridge between inflammatory processes and other biological pathways related to the metabolic syndrome. Our current findings are in close agreement with the only 2 other published studies in children, in which obesity was a risk factor for elevated plasma FABP4 levels $[21,22]$. However, Reinehr et al reported significant correlations between FABP4 and percentage body fat and leptin but the absence of any significant association between FABP and any of the markers of the metabolic syndrome [21]. In a more recent study from Korea, FABP4 concentrations were significantly correlated with BMI and waist circumference, but failed to exhibit a significant association with insulin sensitivity after adjusting for BMI [22]. The larger cohort size in the present study, allowed not only for confirmation of the strong association between FABP concentration and BMI, but also indicated the presence of weaker, albeit significant associations with insulin sensitivity and systemic inflammation.

To further examine the variance in FABP4 levels across obese and non-obese children, we initially examined the frequency of several FABP4 gene polymorphisms in our cohort. This approach revealed that the rs1054135 polymorphism was significantly more prevalent among obese children (Table 2), while no such differences were apparent among the 3 other polymorphisms tested. We are only aware of another published study on FABP4 genomic variants in humans. Indeed, in a population-based genetic study that included 7,899 participants, individuals that carried a T87C polymorphism in the FABP4 gene, which reduces the transcriptional efficiency of the FABP4 gene, had lower serum triglyceride levels and significantly reduced risk for coronary heart disease and type 2 diabetes compared with subjects homozygous for the wild-type allele [26]. Other SNP were not specifically examined, such that comparisons across this study and the present study are not possible. We should emphasize however, that FABP4 is also expressed in activated macrophages [27-29], and high FABP4 concentrations are detected in 
human atherosclerotic lesions [30]. Thus, alleles that reduce FABP4 expression or activity should be metabolically protective, while those associated with higher FABP4 may increase susceptibility. In this regard, genetic variability at the FABP4 as evidenced by rs1054135, increased FABP4 plasma levels in both obese and non-obese children, and its relative preponderance in obese children suggests an interaction between obesity and FABP4 alleles to increase FABP4 circulating levels. Furthermore, the rs16909233 allelic variants were not differentially present in $\mathrm{OB}$ and $\mathrm{NOB}$ children, and did not alter plasma FABP4 levels. However, the presence of this allelic variant seemed to modify insulin resistance in the context of obesity. Taken together, these initial findings in a pediatric community based cohort, suggest that FABP4 genomic variance may be an important determinant for cardiometabolic risk, particularly among obese children.

In summary, we have shown that young obese schoolaged children exhibit higher circulating levels of the pro-atherogenic and pro-inflammatory FABP4, which in turn, may contribute to the risk for reduced insulin sensitivity and increased systemic inflammation, as illustrated by elevated hsCRP levels. Furthermore, gene variants in FABP4 appear to differentially contribute to the pro-inflammatory or diabetogenic potential of obesity during childhood.

\section{List of Abbreviations}

BMI: body mass index; FABP4: fatty acid binding protein 4; HOMA: homeostasis model assessment; hsCRP: high sensitivity $\mathrm{C}$ reactive protein; NOB: non-obese; $\mathrm{OB}$ : obese; SNPs: single nucleotide polymorphisms.

\section{Acknowledgements}

DG is supported by National Institutes of Health grants HL-065270 and HL086662.

\section{Author details \\ 'Department of Pediatrics, Comer Children's Hospital, The University of Chicago, Chicago, IL, USA. ${ }^{2}$ Division of Sleep and Respiratory Medicine, Department of Pediatrics, The Hospital for Sick Children, University of Toronto, Toronto, ON, Canada. ${ }^{3}$ Pediatric Sleep Unit, Division of Neurophysiology, Department of Neurology, Hospital Sant Joan de Déu, Barcelona, Spain.}

\section{Authors' contributions}

$\mathrm{AK}, \mathrm{BB}, \mathrm{MH}, \mathrm{JK}, \mathrm{LKG}, \mathrm{RB}$, OSC collected data, conducted assays, performed data analyses, and contributed to manuscript editing. LKG, RB, OSC and DG recruited subjects. DG initiated the project, reviewed data analysis and drafted the initial manuscript. All authors have reviewed and approved the final manuscript.

\section{Competing interests}

The authors declare that they have no competing interests.

Received: 2 January 2010

Accepted: 15 February 2010 Published: 15 February 2010
References

1. Haslam DW, James WP: Obesity. Lancet 2005, 366:1197-1209.

2. Wang $Y$, Beydoun MA: The obesity epidemic in the United Statesgender, age, socioeconomic, racial/ethnic, and geographic characteristics: a systematic review and meta-regression analysis. Epidemiol Rev 2007, 29:6-28.

3. Ogden $\mathrm{CL}$, Carroll MD, Flegal KM: High body mass index for age among US children and adolescents, 2003-2006. JAMA 2008, 299:2401-5.

4. Visser M, Bouter LM, McQuillan GM, Wener MH, Harris TB: Low-grade systemic inflammation in overweight children. Pediatrics 2001, 107(1):E13.

5. Nemet D, Wang P, Funahashi T, Matsuzawa $Y$, Tanaka S, Engelman L, Cooper DM: Adipocytokines, body composition, and fitness in children. Pediatr Res 2003, 53:148-152.

6. Halle M, Korsten-Reck U, Wolfarth B, Berg A: Low-grade systemic inflammation in overweight children: impact of physical fitness. Exerc Immunol Rev 2004, 10:66-74.

7. Süheyl Ezgü F, Hasanoğlu A, Tümer L, Ozbay F, Aybay C, Gündüz M: Endothelial activation and inflammation in prepubertal obese Turkish children. Metabolism 2005, 54(10):1384-9.

8. Juonala M, Viikari JS, Rönnemaa T, Taittonen L, Marniemi J, Raitakari OT: Childhood C-reactive protein in predicting CRP and carotid intimamedia thickness in adulthood: the Cardiovascular Risk in Young Finns Study. Arterioscler Thromb Vasc Biol 2006, 26(8):1883-8.

9. Brasil AR, Norton RC, Rossetti MB, Leão E, Mendes RP: C-reactive protein as an indicator of low intensity inflammation in children and adolescents with and without obesity. J Pediatr (Rio J) 2007, 83(5):477-80.

10. Sbarbati A, Osculati F, Silvagni D, Benati D, Galiè M, Camoglio FS, Rigotti G, Maffeis $C$ : Obesity and inflammation: evidence for an elementary lesion. Pediatrics 2006, 117(1):220-3.

11. Reinehr T, Kiess W, de Sousa G, Stoffel-Wagner B, Wunsch R: Intima media thickness in childhood obesity: relations to inflammatory marker, glucose metabolism, and blood pressure. Metabolism 2006, 55(1):113-8.

12. Valle Jiménez M, Estepa RM, Camacho RM, Estrada RC, Luna FG, Guitarte FB: Endothelial dysfunction is related to insulin resistance and inflammatory biomarker levels in obese prepubertal children. Eur J Endocrinol 2007, 156(4):497-502.

13. Lee S, Bacha F, Gungor N, Arslanian S: Comparison of different definitions of pediatric metabolic syndrome: relation to abdominal adiposity, insulin resistance, adiponectin, and inflammatory biomarkers. J Pediatr 2008, 152(2):177-84.

14. Tam CS, Clément K, Baur LA, Tordjman J: Obesity and low-grade inflammation: a paediatric perspective. Obes Rev 2009.

15. Zimmerman AW, Veerkamp JH: New insights into the structure and function of fatty acid-binding proteins. Cell Mol Life Sci 2002, 59(7):1096-116.

16. Furuhashi M, Hotamisligil GS: Fatty acid-binding proteins: role in metabolic diseases and potential as drug targets. Nat Rev Drug Discov 2008, 7(6):489-503.

17. Furuhashi M, Fucho R, Görgün CZ, Tuncman G, Cao H, Hotamisligil GS: Adipocyte/macrophage fatty acid-binding proteins contribute to metabolic deterioration through actions in both macrophages and adipocytes in mice. J Clin Invest 2008, 118(7):2640-50.

18. Maeda K, Cao H, Kono K, Gorgun CZ, Furuhashi M, Uysal KT, Cao Q, Atsumi G, Malone H, Krishnan B, Minokoshi Y, Kahn BB, Parker RA, Hotamisligil GS: Adipocyte/macrophage fatty acid binding proteins control integrated metabolic responses in obesity and diabetes. Cell Metab 2005, 1(2):107-19.

19. Xu A, Tso AW, Cheung BM, Wang Y, Wat NM, Fong CH, Yeung DC, Janus ED, Sham PC, Lam KS: Circulating adipocyte-fatty acid binding protein levels predict the development of the metabolic syndrome: a 5year prospective study. Circulation 2007, 115(12):1537-43.

20. Cabré A, Lázaro I, Girona J, Manzanares JM, Marimón F, Plana N, Heras M, Masana L: Plasma fatty acid binding protein 4 is associated with atherogenic dyslipidemia in diabetes. J Lipid Res 2008, 49(8):1746-51.

21. Reinehr T, Stoffel-Wagner B, Roth CL: Adipocyte fatty acid-binding protein in obese children before and after weight loss. Metabolism 2007, 56(12):1735-41.

22. Yun KE, Kim SM, Choi KM, Park HS: Association between adipocyte fatty acid-binding protein levels and childhood obesity in Korean children. Metabolism 2009, 58(6):798-802. 
23. Matthews DR, Hosker JP, Rudenski AS, Naylor BA, Treacher DF, Turner RC: Homeostasis model assessment: insulin resistance and $\beta$-cell function from fasting plasma glucose and insulin concentrations in man. Diabetologia 1985, 28:412-419.

24. Ernst ND, Obarzanek E: Child health and nutrition: obesity and high blood cholesterol. Prev Med 1994, 23(4):427-36.

25. Popkin BM, Gordon-Larsen P: The nutrition transition: worldwide obesity dynamics and their determinants. Int J Obes Relat Metab Disord 2004, 28(Suppl 3):S2-9.

26. Tuncman G, Erbay E, Hom X, De Vivo I, Campos H, Rimm EB, Hotamisligil GS: A genetic variant at the fatty acid-binding protein aP2 locus reduces the risk for hypertriglyceridemia, type 2 diabetes, and cardiovascular disease. Proc Natl Acad Sci USA 2006, 103(18):6970-5.

27. Fu Y, Luo N, Lopes-Virella MF: Oxidized LDL induces the expression of ALBP/aP2 mRNA and protein in human THP-1 macrophages. I Lipid Res 2000, 41(12):2017-23.

28. Fu Y, Luo N, Lopes-Virella MF, Garvey WT: The adipocyte lipid binding protein (ALBP/aP2) gene facilitates foam cell formation in human THP-1 macrophages. Atherosclerosis 2002, 165(2):259-69.

29. Liu QY, Quinet E, Nambi P: Adipocyte fatty acid-binding protein (aP2), a newly identified LXR target gene, is induced by LXR agonists in human THP-1 cells. Mol Cell Biochem 2007, 302(1-2):203-13.

30. Boord JB, Maeda K, Makowski L, Babaev VR, Fazio S, Linton MF, Hotamisligil GS: Adipocyte fatty acid-binding protein, aP2, alters late atherosclerotic lesion formation in severe hypercholesterolemia. Arterioscler Thromb Vasc Biol 2002, 22(10):1686-91.

doi:10.1186/1476-511X-9-18

Cite this article as: Khalyfa et al:: Fatty-acid binding protein 4 gene variants and childhood obesity: potential implications for insulin sensitivity and CRP levels. Lipids in Health and Disease 2010 9:18.

\section{Submit your next manuscript to BioMed Central and take full advantage of:}

- Convenient online submission

- Thorough peer review

- No space constraints or color figure charges

- Immediate publication on acceptance

- Inclusion in PubMed, CAS, Scopus and Google Scholar

- Research which is freely available for redistribution

Submit your manuscript at www.biomedcentral.com/submit
Biomed Central 